This is the peer reviewed version of the following article: Andersen PK, Jensen TH, Lykke-Andersen S. (2013).

Making ends meet: coordination between RNA 3'-end processing and transcription initiation. Wiley Interdiscip Rev RNA. 4:233-246,

which has been published in final form at doi: 10.1002/wrna.1156. This article may be used for non-commercial purposes in accordance with

Wiley Terms and Conditions for self-archiving.

\title{
Making ends meet: coordination between RNA 3'end processing and transcription initiation
}

\begin{tabular}{|r|l|}
\hline Journal: & WIRES RNA \\
\hline Manuscript ID: & RNA-548.R1 \\
\hline Wiley - Manuscript type: & Advanced Review \\
\hline Date Submitted by the Author: & n/a \\
\hline Complete List of Authors: & $\begin{array}{l}\text { Andersen, Pia; Aarhus University, Department of Molecular Biology } \\
\text { Jensen, Torben; Aarhus University, Department of Molecular Biology } \\
\text { Lykke-Andersen, Søren; Aarhus University, Department of Molecular } \\
\text { Biology }\end{array}$ \\
\hline Keywords: & $\begin{array}{l}\text { 3'end processing, transcription initiation, recycling of RNA polymerase II, } \\
\text { gene-communication, transcription regulation }\end{array}$ \\
\hline $\begin{array}{r}\text { Choose 1-3 topics to } \\
\text { categorize your article: }\end{array}$ & 3-prime end processing (RFAE) < RNA Processing (RFAA) \\
\hline \multicolumn{2}{|l}{} \\
\hline
\end{tabular}


Please select the appropriate article type (per your Contributor's Agreement) by double-clicking on the associated check box.

\begin{tabular}{|l|l|l|l|}
\hline$\square$ & Overview & $\begin{array}{l}\text { Overviews will provide a broad and relatively non-technical treatment of } \\
\text { important topics at a level suitable for advanced students and for researchers } \\
\text { without a strong background in the field. }\end{array}$ & $\begin{array}{l}5,000-8,000 \text { words } \\
\leq 16 \text { figures/tables } \\
50-100 \text { references }\end{array}$ \\
\hline$X$ & $\begin{array}{l}\text { Advanced } \\
\text { Review }\end{array}$ & $\begin{array}{l}\text { Advanced Reviews, aimed at researchers and advanced students with a strong } \\
\text { background in the subject, will review key areas of research in a citation-rich } \\
\text { format similar to that of leading review journals. }\end{array}$ & $\begin{array}{l}4,000-6,000 \text { words } \\
\leq 10 \text { figures/tables } \\
50-75 \text { references }\end{array}$ \\
\hline$\square$ & $\begin{array}{l}\text { Focus } \\
\text { Article }\end{array}$ & $\begin{array}{l}\text { Focus articles are short articles, sometimes included within a larger article, } \\
\text { that describe specific real-world issues, examples, implementations, etc. } \\
\text { These articles will be technical in nature. }\end{array}$ & $\begin{array}{l}2,500-4,000 \text { words } \\
\leq 7 \text { figures/tables } \\
40-60 \text { references }\end{array}$ \\
\hline$\square$ & Opinion & $\begin{array}{l}\text { Opinions provide a forum for thought-leaders, hand-picked by the editors, to } \\
\text { provide a more individual perspective on the field in question. }\end{array}$ & $\begin{array}{l}2,000-4,000 \text { words } \\
\leq 5 \text { figures/tables } \\
30-60 \text { references }\end{array}$ \\
\hline
\end{tabular}

\section{Article title: Making ends meet: coordination between RNA 3'end processing and transcription initiation}

Full name and affiliation; email address if corresponding author; any conflicts of interest

\section{First author: Full name and affiliation; plus email address if corresponding author} Pia K. Andersen, Centre for mRNP Biogenesis and Metabolism, Department of Molecular Biology and Genetics, Aarhus University, C.F. Møllers Alle 3, Bldg. 1130, DK-8000, Aarhus, Denmark

\section{Second author: Full name and affiliation; plus email address if corresponding author} Torben Heick Jensen*, Centre for mRNP Biogenesis and Metabolism, Department of Molecular Biology and Genetics, Aarhus University, C.F. Møllers Alle 3, Bldg. 1130, DK8000, Aarhus, Denmark, thj@mb.au.dk Third author: Full name and affiliation; plus email address if corresponding author Søren Lykke-Andersen*, Centre for mRNP Biogenesis and Metabolism, Department of Molecular Biology and Genetics, Aarhus University, C.F. Møllers Alle 3, Bldg. 1130, DK8000, Aarhus, Denmark, sla@mb.au.dk

Abstract

RNA polymerase II (RNAPII)-mediated gene transcription initiates at promoters and ends at terminators. Transcription termination is intimately connected to 3 'end processing of the produced RNA and already when loaded at the promoter, RNAPII starts to become configured for
Comment [A1]: Remember that you are writing for an interdisciplinary audience: please be sure to discuss interdisciplinary themes, issues, debates, etc. where appropriate.

PLEASE READ ALL ‘COMMENT’ TEXT BELOW BEFORE PREPARING YOUR ARTICLE.

Refer to the Guide for Authors for more detailed instructions, or contact rna@wiley.com.

Comment [A2]: Regardless of what type of article you are submitting, please bear in mind that WIRES RNA is a forum for review articles, rather than primary literature describing the results of original research.
Comment [A3]: The title should not exceed 30 words. Within that limit a longer title can increase the online visibility of your article. Please be original and try to include key words.

Comment [A4]: The preferred (but optional) format for author names is First Name, Middle Initial, Last Name. Copy cells as necessary for additional authors. Please use an asterisk $(*)$ to indicate the corresponding author name.

Wiley-Blackwell also requires that all authors disclose any potential sources of conflict of interest. Any interest or relationship, financial or otherwise, that might be perceived as influencing an author's objectivity is considered a potential source of conflict of interest. The existence of a conflict of interest does not preclude publication in WIRES RNA. 
this downstream event. Conversely, RNAPII is 'reset' as part of the 3'end processing/termination event, thus preparing the enzyme for its next round of transcription - possibly on the same gene. There is both direct and circumstantial evidence for preferential recycling of RNAPII from the gene terminator back to its own promoter, which supposedly increases the efficiency of the transcription process under conditions where RNAPII levels are rate limiting. Here, we review differences and commonalities between initiation and 3'end processing/termination processes on various types of RNAPII transcribed genes. In doing so, we discuss the requirements for efficient 3'end processing/termination and how these may relate to proper recycling of RNAPII.]

The conversion of genetic information into functional molecules begins with gene transcription. In eukaryotes, multisubunit RNA polymerases (RNAPs) execute the transcription of nuclear-encoded genes. There are five eukaryotic RNAPS - RNAPI, II, III, IV and V, where the latter two only exist in plants $^{1,2}$. RNAPII appears to be the most versatile of these enzymes, both with respect to the types of transcription units it engages and in terms of the cellular levels, sizes and physical properties of the generated RNA molecules, which include both protein-coding mRNA as well as long- and short non-coding (nc)RNA.

Common to all genes is that they are linear entities confined by promoters and terminators that dictate where transcription starts and ends. Where studied, transcription termination is tightly coupled to the 3 'end processing of the produced RNA molecule and the combined process is necessary for release of the transcript and the RNA polymerase from the gene template as well as from each other ${ }^{3-5}$. In addition to this crucial step in gene expression, recent studies from several laboratories suggest that RNA 3'end processing/transcription termination can both positively and 


\section{Transcription termination}

After transcribing the gene body, RNAPII reaches the terminator region downstream of the RNA 3'end processing site. It is generally perceived that transcriptional termination is tightly coordinated with RNA 3'end processing, but no unifying model exists for termination of transcription on all types of RNAPII genes. The process is best described for genes encoding polyadenylated RNA (hereafter referred to as 'polyA genes'), for which two models have been proposed. The 'allosteric' model suggests that RNAPII undergoes conformational changes due to dissociation of elongation factors and/or association of termination factors upon passage of the 3 'end processing signal, which 


\section{Setting and resetting RNAPII}

During the transcription process the RNAPII complex is subject to extensive changes in modification. A central platform for this modulation is the C-terminal domain (CTD) of the largest subunit of RNAPII, which acts as a scaffold for interactions with multiple factors involved in transcription initiation, elongation and termination as well as with factors important for co-transcriptional maturation of the RNA product. The CTD contains a conserved heptad repeat sequence (consensus: $\left.\mathrm{Tyr}_{1} \mathrm{Ser}_{2} \mathrm{PrO}_{3} \mathrm{Thr}_{4} \mathrm{Ser}_{5} \mathrm{PrO}_{6} \mathrm{Ser}_{7}\right)$ and most of its amino acid residues can be post-translationally modified (Figure 1). This dynamic property of the CTD is of great importance for the transcription cycle as it assists the coordination between the many facets of transcription and RNA processing ${ }^{33-37}$. The patterns of phosphorylation of serines $2(\operatorname{Ser} 2 \mathrm{P})$ and $5(\mathrm{Ser} 5 \mathrm{P})$ and the consequences thereof have been the focus of particular intense investigations, but recent attention has also been directed towards phosphorylation of Tyr1 (Tyr1P), Thr4 (Thr4P) and Ser7 (Ser7P) that appear to be important for specific types of $3^{\prime}$ end processing reactions ${ }^{38-43}$. 


\begin{abstract}
Although the phosphorylation pattern of the CTD is gene specific some overall features relate to the distance travelled by RNAPII away from the promoter (see Figure 1). In general, RNAPII is loaded on the PIC with a hypophosphorylated CTD, which then becomes Ser5 phosphorylated during the initial phases of transcription. As RNAPII travels through the gene Ser5P gradually declines and Ser2P levels rise. In yeast, the switch from dominating Ser5P to Ser2P is estimated to occur $\sim 450 \mathrm{bp}$ downstream of the $\mathrm{TSS}^{44,45}$, after which high levels of Ser2P persist until a terminator is reached. Ser7P and Thr4P display roughly similar patterns to Ser5P and Ser2P, respectively (Figure 1) ${ }^{42,45,46}$. Thus, when RNAPII encounters a terminator on short genes ( $<450 \mathrm{bp})$ the CTD is mainly in a Ser5P/Ser7P state, whereas on longer genes ( $>450$ bp) Ser2P/Thr4P will predominate. Accordingly, the associated 3 'end processing/termination processes on short and long genes have evolved to be differentially stimulated by the specific modification of the CTD matching the time of its usage (see below and Figure $2 \mathrm{~A}$ ). An interesting new discovery here is the observation from yeast that although the profile of Tyr1P follows that of Ser2P it declines earlier than Ser2P and before RNAPII reaches the $3^{\prime}$ end processing signal (Figure 1$)^{38}$. This allows for the dismantling of specific elongation factors as well as the binding of specific termination factors and Tyr1P thereby 'shields' the CTD from becoming prematurely termination-prone before reaching the gene end. It is likely that such coordinated departure of elongation factors and entry of termination factors constitutes a checkpoint for efficient transcription termination.
\end{abstract}

Some distance into the terminator region, the CTD is eventually dephosphorylated ${ }^{45,47-49}$, and it is generally observed that RNAPII which is not bound to the DNA template is hypophosphorylated ${ }^{50,51}$. It therefore appears that RNAPII can be 'reset', at least partially, in preparation for its next round of transcription either prior to, or concomitant with its termination. Another important, albeit less well studied, aspect of such RNAPII resetting is its release of the produced RNA. This can occur while RNAPII is still attached to, or after it has been dismantled from, the chromatin template ${ }^{52-55}$. Interestingly, coupled in vitro transcription/3'end formation assays performed in HeLa cell nuclear extracts have revealed that a nascent mRNA can remain attached to the RNAPII CTD even after 
cleavage at its polyadenylation site and is only released upon productive $3^{\prime}$ end polyadenylation ${ }^{56}$. Thus, at least in some situations, all stages of RNA 3'end processing would have to be completed before RNAPII can be recycled to perform another round of initiation.

\section{RNAPII-transcribed genes - the long and the short of it}

Above RNAPII transcription has been generalized, but in reality there are variations for each individual gene type. RNAPII-transcribed genes can broadly be placed into three categories depending on the nature of the produced mature RNA: (1) protein-coding genes, which in many metazoans fall in two different groups, namely (1a) those encoding polyadenylated mRNA and (1b) those encoding replication-dependent non-adenylated histone mRNA, (2) short ncRNA genes, such as those encoding a subset of sn/snoRNAs and (3) long non-coding (Inc)RNA genes. We will not discuss the latter class further here, since only little general knowledge has been obtained on features of its transcription initiation and 3'end processing/termination.

Even though promoters vary between and within these categories in terms of which complement of transcription factors is bound, a common (sub)set of GTFs are believed to be positioned at the core of committing RNAPII for transcription ${ }^{13,57-61}$. Additionally, the machineries that mediate RNA 3'end processing and RNAPII termination on these types of genes display commonalities as well as major differences. In the remainder of the review we will mainly focus on knowledge from metazoan organisms except where indicated.

\section{Protein-coding genes with a polyA terminator}

The vast majority of protein-coding genes produce polyadenylated mRNA with 5'- and 3'untranslated regions (UTRs), an open reading frame (ORF), and in most cases several introns. The 


\begin{abstract}
position of the $3^{\prime}$ end of the mature transcript is dictated by the RNA polyA site, however, after its
\end{abstract} passage, RNAPII continues into the terminator region where transcription eventually ceases. The distance from the TSSs of polyA genes to their polyA sites (i.e. the length of the gene body) varies in size from $\sim 500$ to several millions of base pairs $(\mathrm{bp})$. Furthermore, the distance covered by RNAPII from the polyA site and until it terminates differs between, and within, genes from a few hundred to several thousand bp (Figure $2 A)^{46,49}$. 3'end processing of polyA gene products is driven by two enzymatic reactions - pre-mRNA cleavage and 3'end polyadenylation of the upstream cleavage fragment (Figure 2B). A polyA signal consists of several RNA elements of which the best-defined is the polyA-hexamer AWUAAA ( $W$ is either $A$ or $U$ ) found 1-40 nt upstream of the cleavage site in the majority of metazoan RNAPII transcribed protein coding polyA genes ${ }^{62-65}$. Additionally, a polyA signal consists of a less well-defined 'downstream sequence element' (DSE) as well as 'auxiliary sequences' that can be positioned up- and downstream of the cleavage site. The factors and enzymes that recognize these sequences and finally mediate the cleavage and polyadenylation reaction are in tight association in a major $3^{\prime}$ end processing complex, which broadly defined contains $>85$ proteins ${ }^{4,66,67}$. A core of these can be divided into four major multisubunit complexes (so-called 'factors'; Figure $2 B)^{68}$ : (1) CPSF (cleavage and polyadenylation specificity factor), which recognizes the polyAhexamer (or functionally equivalent sequences) and contains the CPSF73 enzyme responsible for the endonucleolytic cleavage reaction ${ }^{69}$, (2) CstF (cleavage stimulatory factor) that binds the DSE and stimulates the cleavage reaction ${ }^{70}$, and $(3,4)$ cleavage factors I and II $\left(\mathrm{CFI}_{\mathrm{M}}\right.$ and $\left.\mathrm{CFII}_{\mathrm{M}}\right)$, where $\mathrm{CFI}_{\mathrm{M}}$ recognizes an auxiliary sequence upstream the cleavage site $^{71}$. After transcript cleavage, CPSF directs the polyadenosine polymerase (PAP) to add the polyA-tail, a coordination of cleavage and polyadenylation, which ensures that the 3'end is rapidly protected from 3'-5' exonucleases. During polyA-tail synthesis, nuclear polyA-binding protein (PABPN1) binds to the nascent stretch of PAPproduced $A^{\prime}$ 's and strongly stimulates further polyadenylation by retaining CPSF at the polyadenylation signal ${ }^{72,73}$. The interaction between PABPN1 and CPSF with the polyA tail persists until it has reached $\sim 250 \mathrm{~A}^{\prime}$ s after which the stimulation by CPSF is disrupted ${ }^{73}$. 


\section{Replication-dependent histone genes}

Unique among metazoan protein-coding genes are those encoding the replication-dependent histones (hereafter referred to as 'histone genes'). At least three features set this class of genes apart from the bulk of protein-coding genes: (1) they are located in clusters in the genome, (2) they are intronless, and (3) the encoded mRNA is 3'end processed in a specialized manner ${ }^{82-84}$. Furthermore, histone genes are generally shorter than their polyA gene counterparts with gene 
body lengths from $\sim 350$ to $\sim 800 \mathrm{bp}$ (Based on data from ref. 83). In contrast to polyA gene terminators, RNAPII is detectable on histone genes as a relatively narrow peak within a $\sim 1 \mathrm{~kb}$ region downstream of the histone 3'end processing signal, indicating that transcription termination occurs in a more efficient and homogenous manner (Figure $2 \mathrm{~A})^{46,85}$. This is potentially aided by the presence of a strong RNAPII arrest/pause site immediately downstream of the $3^{\prime}$ end processing signal ${ }^{86}$. Two sequence elements are required for proper 3'end processing of histone mRNAs, a stem-loop and a purine-rich 'histone downstream element' (HDE) located 15-20 nt downstream of the stem-loop. The histone pre-mRNA is endonucleolytically cleaved between these two elements ${ }^{87,88}$, resulting in a mature transcript containing a 3'stem-loop potentially protecting against 3'-5' degradation (Figure 2B). Interestingly, as for polyA site cleavage the responsible endoribonuclease is $\mathrm{CPSF}^{89,90}$. In addition, cleavage/polyadenylation factors CPSF, CstF77, CstF64, Fip1 and Symplekin are also involved in histone mRNA $3^{\prime}$ end processing ${ }^{91,92}$. Besides this overlap in factor usage, the implicated complexes are different. The histone stem-loop is bound by 'stem loop binding protein' (SLBP), which facilitates the binding of U7 snRNA to the HDE by basepairing ${ }^{93}$. SLBP bound to the stem-loop interacts with ZFP100 94 , which in turn associates with the U7 snRNA-associated protein Lsm11 thus bridging the stem-loop and the $\mathrm{HDE}^{95,96}$. How CPSF73 is recruited to the cleavage site is still not known, but it has been suggested that FLASH, another essential component of the histone mRNA 3'end formation machinery, mediates the contact between CPSF73 and the pre-mRNA (Figure $2 \mathrm{~B})^{97}$.

Any coupling between transcription and RNA 3'end processing on histone genes is only poorly understood currently. FLASH, SLBP, CPSF73 and CstF77 are present at the histone promoter ${ }^{43,49,98}$ and the former two proteins co-localize with the histone gene transcription factor NPAT, which may imply pre-loading of $3^{\prime}$ end processing factors ${ }^{98}$. Interestingly, CTD-Thr4P is required for histone mRNA 3'end processing whereas it is dispensable for polyadenylation of polyA genes ${ }^{43}$. In line with this, Thr4P is essential in vertebrates ${ }^{42}$, but not in budding and fission yeasts ${ }^{99,100}$, consistent with the fact that no specialized 3'end processing machinery exists for histone genes in these species. There are conflicting observations about the involvement of Ser2P in histone mRNA 3'end processing ${ }^{101,102}$. 


\section{U snRNA genes}

RNAPII transcribes a subset of autonomous small ncRNA genes, including some snRNA and snoRNA loci ${ }^{103}$. The resulting RNAs are usually involved in the processing/modification of other RNA molecules. Besides being short ( 150-350 nt; Figure 2A), these RNAs are characterized by their lack of introns and their production from genes having specialized promoters and terminators ${ }^{57,104}$. The human $\mathrm{U} 1$ and $\mathrm{U} 2$ snRNA-encoding genes are most comprehensively described with respect to $3^{\prime}$ end processing and transcription termination and will be discussed in the following paragraphs.

U1 and U2 snRNA gene promoters contain two important regions; the proximal and distal sequence elements (PSE and DSE), respectively ${ }^{105}$. Lack of either of these reduces RNA levels by more than 100 -fold ${ }^{106}$. Like other RNAPII-genes, U1 transcription relies on GTFs such as TFIIA, TFIIB, TFIIF, TFIIE ${ }^{60}$ together with TBP ${ }^{107}$. However, TBP and a subset of its interacting factors (TAFs) are recruited to the U1 promoter in complex with the snRNA-activating protein complex (SNAPc) and not in context of the usual TFIID GTF ${ }^{61,107}$. The general involvement of $U$ snRNAs (and snoRNAs) in RNA metabolism requires their robust expression, which is probably governed by a specialized mode of transcription as well as the long half-lives of these molecules. 3'end processing of $U$ snRNAs is accomplished by a dedicated machinery, which is different between metazoans and yeast. In animals, a protein complex called Integrator carries out 3'end formation involving an endonucleolytic cleavage event upstream of the $3^{\prime}$ end-positioned so-called 3 'box (Figure $\left.2 \mathrm{~B}\right)^{108}$. The endonuclease, Int11, and another Integrator subunit, Int9, are homologs of CPSF73 and CPSF100, respectively ${ }^{108}$. Apart from these factors, the snRNA $3^{\prime}$ end processing complex is completely 


\begin{abstract}
different from the described mRNA 3 'end processing complexes and no polyadenylation of the naked snRNA 3'end occurs. Instead, it appears that the $U$ snRNA is protected against degradation by upstream secondary structures or bound proteins. How processing at the 3 'box connects with termination of RNAPII is virtually unknown. Nuclear run-on (NRO) analyses suggested that the primary transcript produced from the $\mathrm{U} 2$ gene can extend at least $~ 800 \mathrm{nt}$ from the TSS, which means that RNAPII, similar to histone genes, may continue to transcribe $\sim 600$ bp past the $3^{\prime}$ box ${ }^{109}$. In contrast, termination on the U1 snRNA gene was found to occur immediately downstream of the $3^{\prime}$ box $^{109,110}$. However, this observation is probably affected by the many genomic copies of U1, which diverge in their sequences downstream of the gene body. Indeed, unpublished data imply that RNAPII transcription here can also continue further downstream (D. O’Reilly and S. Murphy, personal communication).
\end{abstract}

The CTD of RNAPII is essential for proper $3^{\prime}$ end formation of U1 and U2 snRNA ${ }^{111-113}$ and its phosphorylation status is central for this dependency ${ }^{39-41}$. In particular, Ser7P appears to be essential for the process ${ }^{39}$. The Integrator subunit Int11 interacts with the CTD, but it is most efficiently recruited to Ser2P/Ser7P configured heptad repeats ${ }^{40}$, which implies that Integrator-mediated 3'end processing is only efficient within a rather narrow window of distance from the TSS where both these modifications are present at the same time. Since Ser7 generally starts to become dephosphorylated when RNAPII travels further than $\sim 450$ bp this may explain why increasing the distance between the promoter and the 3 'box of the U1 snRNA gene decreases the efficiency of 3'end processing ${ }^{114}$.

Similar to the early recruitment of 3 'end processing factors on polyA genes, the Integrator complex (Int2 and Int9-11) is found at the promoter of snRNA genes ${ }^{108}$. It is not known whether initial recruitment occurs independently of RNAPII, but since several studies have shown that elements in snRNA promoters are needed for efficient U snRNA $3^{\prime}$ end processing ${ }^{104,115,116}$, this would be in accordance with promoter-specific Integrator recruitment and its later handover to RNAPII. 


\section{Functional communication between terminator and promoter}

Where most of the above described interactions between nascent RNA 3'end processing factors and transcription take place within the same transcription cycle, evidence for a functional link between the $3^{\prime}$ end processing/termination reaction back to the promoter is emerging. A first indication was the discovery of a transcription-dependent physical interaction between terminator and promoter via so-called gene loops. In yeast, loop formation is mediated by an interaction between TFIIB and the Ser5-phosphatase, 3'end processing and transcription elongation factor Ssu72 $p^{7,9,131-133}$. Gene loops result in close contact between the promoter and terminator and are suggested to facilitate 
transcription re-initiation and to impose directionality onto the promoter ${ }^{10,11,133,134}$. Moreover, several reports imply that impairment of 3 'end processing and/or transcription termination leads to decreased transcription initiation: In a genome-wide study on yeast cells, it was observed that termination was impeded on both protein coding and small non-coding genes upon inhibition of the phosphatase activity of Ssu72 $\mathrm{p}^{47}$. In parallel, a general drop in RNAPII levels at the promoters and in the gene bodies of the termination-impeded genes was detected. Similar effects were reported by a series of study examples using individual reporter genes. For instance, inactivation of Rat1p (yeast homolog of XRN2) was shown to decrease levels of RNAPII at the promoter and inside the gene body of the assayed $A D H 1$ gene ${ }^{135}$ and depletion of human Senataxin led to elevated levels of RNAPII in the terminator region of the $\beta$-actin gene accompanied by a significant decrease at the promoter ${ }^{27}$. These examples do not per se imply recycling within the same gene, since lowered levels of RNAPII at the investigated promoters could be a consequence of global sequestration in terminator regions. However, in two recent studies similar phenomena were detected on genes with 3'end processing/termination defects imposed in $\mathrm{cis}^{6,8}$. In the first, compromised 3'end processing/termination caused by a single point mutation of a polyA signal yielded a lower transcription initiation rate as measured by NRO as well as promoter-ChIP of RNAPII and the two GTFs TBP and TFIIB ${ }^{8}$. Surprisingly, complementary ChIP analysis revealed that the CTD of RNAPII present downstream of the mutated polyA site, and supposedly still attached to the nascent uncleaved RNA, was largely devoid of Ser2P and Ser5P and an equally curious elevated level of both TBP and TFIIB could be measured at the same positions ${ }^{8}$. While these phenomena were consequences of the impaired 3'end processing/termination, they may also reflect natural processes that just take place with faster kinetics at a functional terminator. Thus, perhaps dephosphorylated RNAPII can bind some GTFs already before disengaging from the chromatin template, which is in agreement with the suggestion that RNAPII can be prepared for the next round of transcription before or concomitant with termination. Furthermore, it was recently shown that the described 3'end processing/termination defect correlated with the disappearance of a detectable promoter- 
terminator loop, which implies that gene looping could be responsible for efficient recycling of RNAPII back to the promoter ${ }^{11}$. In a second study, polyA genes of different lengths were analyzed and it was found that a short $<450 \mathrm{bp}$ gene was transcriptionally repressed at the initiation level compared to its longer (>450bp) counterparts. Transcription repression required that the gene harboured a polyA terminator; i.e. repression was relieved upon its replacement by a replication dependent histone gene-terminator ${ }^{6}$. This implies a strong context-specific requirement for the efficient communication between 3'end processing/termination signals and the promoter. Assuming that the switch from dominating Ser5P to Ser2P also happens $\sim 450 \mathrm{bp}$ downstream of the TSS in mammalian species, there is a striking correlation between the predicted RNAPII-CTD phosphorylation status and the efficiency by which the different 3 'end processing signals stimulate transcriptional re-initiation (see Conclusion for further elaboration). A somewhat surprising addition to these observations is that the actual RNA polyadenylation event also appears to affect transcription initiation as cells treated with cordycepin, a drug that inhibits the addition of adenosines to the elongating polyA tail, displayed decreased promoter RNAPII occupancy at polyA genes concomitant with increased RNAPII signals downstream of the corresponding polyA sites. In contrast, RNAPII occupancy in the terminator region of histone genes were not affected by cordycepin $^{46}$. The mechanism underlying these observations is not understood, but taken together with the finding that the actual polyadenylation event is needed for release of the mRNA from $\mathrm{RNAPII}^{56}$, it is possible that proper transcription termination in some cases depends on polyadenylation, which in turn affects re-initiation (Figure 1).

\begin{tabular}{|l|}
\hline Sidebar title \\
[Please include sidebars in the body of the text where appropriate]
\end{tabular}

Conclusion
Comment [A5]: You are encouraged to include sidebars ("boxed" information that is relevant to but separate from the main text) especially to highlight contemporary interdisciplinary themes. Each sidebar should be a maximum of 250 words. Do not include more than two sidebars. 


\begin{abstract}
Although not formally demonstrated for all gene classes, it is generally assumed that transcription termination is intricately coupled to RNA 3'end processing. The 'strength' of the 3'end processing signal and its surrounding terminator region determine how rapidly the RNA is processed and how efficiently RNAPII terminates. While a major determinant for 3 'end processing strength is the composition of the signal itself in terms of elements and their sequences, it is also clear that the distance to the TSS plays a decisive role in how well a given signal is utilized. Due to CTDmodification changes as a function of RNAPII transcriptional progress, a promoter proximal polyA signal is not recognized as efficiently as a distal one and, conversely, a distal snRNA 3'end processing signal functions worse than a proximal one. In addition, RNA 3 'end processing efficiency is influenced by upstream RNA processing events; e.g. splicing of the last intron is stimulatory for the cleavage/polyadenylation reaction as well as for release of the polyadenylated mRNA from RNAPII ${ }^{56,136-139}$. Similarly, $3^{\prime}$ end processing of snRNAs is promoted by 7-methyl-G capping of the RNA $5^{\prime}$ end ${ }^{140}$. Finally, as many $3^{\prime}$ end processing factors are already recruited at the promoter, it is possible that critical decisions can be made very early in the transcription process.
\end{abstract}

The accumulating body of evidence highlighting the importance of productive 3 'end processing/termination for transcriptional re-initiation of the same gene calls for mechanism(s) to recycle RNAPII from the terminator back to the promoter. Gene-looping from 3'end processing sites to promoters may be one way to maintain sufficient local concentrations of RNAPII within each individual gene circuit. Alternatively, the compartmentalization of genes into a spatially confined environment (aka 'gene factories'), could increase the chances for an RNAPII complex to re-initiate on the same recently transcribed gene, simply by being in proximity ${ }^{141,142}$. This was shown for gene loci on polytene chromosomes in $D$. melanogaster salivary glands ${ }^{12}$, and it may be an important feature for clustered genes. As the availability of RNAPII varies between different conditions and cell types there may not always be a need for intragenic recycling of RNAPII ${ }^{143}$ However, in favor of a general importance of recycling, it was recently shown that RNAPII is present in surprisingly few copies per cell in proliferating S. pombe ( 1 molecule per gene $)^{144}$. 
If the lowered transcription initiation activity of genes undergoing defective/weak 3'end processing/termination is indeed caused by inefficient RNAPII recycling, what is then causing this? When RNAPII encounters a weak/defective $3^{\prime}$ end processing signal, it may become somewhat prone for termination while still being partially fit for continued elongation. Such an 'upset' polymerase may terminate erroneously at a more or less random position without being properly reset - i.e. without proper CTD dephosphorylation and/or without release of the RNA (both the gene-body encoded RNA and the polymerase-associated RNA) - and therefore not be prepared for re-initiation (Figure 1). In fact, the major determinant for efficient recycling may be the ability of RNAPII to be reset during termination. Such resetting would then depend on the kinetics of 3 'end processing and termination, which in turn are governed by the strength of the encountered processing signal.

What then is an efficient terminator? In order to avoid transcriptional interference into a downstream gene, termination is required, especially in cases where genes are closely spaced. Nonetheless, even when the $3^{\prime}$ end processing signal is supposedly strong, RNAPII often travels far into the terminator - up to $1 \mathrm{~kb}$ on histone and snRNA genes and up to several $\mathrm{kb}$ on polyA genes. The rather broad distribution of RNAPII molecules in the terminator region - especially on polyA genes - implies that completion of the transcription process is somewhat stochastic and depends on limiting events/factors. This may reflect an inherent disinclination for an elongating RNAPII to terminate, ensuring that it only happens when the transcription and RNA processing events have been completed. Although the resetting and recycling processes of RNAPII need to be studied in much greater detail, the fact that the CTD can be dephosphorylated a short distance into the terminator region and that the unprotected 3'RNA trailing from the RNAPII is normally rapidly degraded implies that resetting of RNAPII can take place on the chromatin template. Intuitively, this appears beneficial if recycling is to be tightly controlled. Perhaps the final release from the terminator is even determined by the encounter with a re-initiation complex bound promoter possibly from the same gene. 


\section{Acknowledgements}

We thank Shona Murphy and Manfred Schmid for critical reading of this manuscript. Work in the authors' laboratory on this topic is supported by the Danish National Research Foundation and the Lundbeck Foundation.

Notes

[Please add any notes here]

References

1. Vannini A, Cramer P: Conservation between the RNA polymerase I, II, and III transcription initiation machineries. Mol Cell 2012;45:439-46.

2. Haag JR, Pikaard CS: Multisubunit RNA polymerases IV and V: purveyors of non-coding RNA for plant gene silencing. Nat Rev Mol Cell Biol 2011;12:483-92.

3. Kuehner JN, Pearson EL, Moore C: Unravelling the means to an end: RNA polymerase II transcription termination. Nat Rev Mol Cell Biol 2011;12:283-94.

4. Proudfoot NJ: Ending the message: poly(A) signals then and now. Genes Dev 2011;25:1770-82.

5. Richard P, Manley JL: Transcription termination by nuclear RNA polymerases. Genes Dev 2009;23:1247-69.

6. Andersen PK, Lykke-Andersen S, Jensen TH: Promoter-proximal polyadenylation sites reduce transcription activity. Genes Dev 2012;26:2169-79.

7. Ansari A, Hampsey M: A role for the CPF $3^{\prime}$-end processing machinery in RNAP II-dependent gene looping. Genes Dev 2005;19:2969-78.

8. Mapendano CK, Lykke-Andersen S, Kjems J, et al.: Crosstalk between mRNA 3' end processing and transcription initiation. Mol Cell 2010;40:410-22.

9. O'Sullivan JM, Tan-Wong SM, Morillon A, et al.: Gene loops juxtapose promoters and terminators in yeast. Nat Genet 2004;36:1014-8.

10. Tan-Wong SM, Wijayatilake HD, Proudfoot NJ: Gene loops function to maintain transcriptional memory through interaction with the nuclear pore complex. Genes Dev 2009;23:2610-24.

11. Tan-Wong SM, Zaugg JB, Camblong J, et al.: Gene loops enhance transcriptional directionality. Science 2012;338:671-5.

12. Yao J, Ardehali MB, Fecko CJ, et al.: Intranuclear distribution and local dynamics of RNA polymerase II during transcription activation. Mol Cell 2007;28:978-90. 
13. Baumann M, Pontiller J, Ernst W: Structure and basal transcription complex of RNA polymerase II core promoters in the mammalian genome: an overview. Mol Biotechnol 2010;45:241-7.

14. Carninci P, Sandelin A, Lenhard B, et al.: Genome-wide analysis of mammalian promoter architecture and evolution. Nat Genet 2006;38:626-35.

15. Malik S, Roeder RG: The metazoan Mediator co-activator complex as an integrative hub for transcriptional regulation. Nat Rev Genet 2010;11:761-72.

16. Cramer P: Structure and function of RNA polymerase II. Adv Protein Chem 2004;67:1-42.

17. Fuda NJ, Ardehali MB, Lis JT: Defining mechanisms that regulate RNA polymerase II transcription in vivo. Nature 2009;461:186-92.

18. Sikorski TW, Buratowski S: The basal initiation machinery: beyond the general transcription factors. Curr Opin Cell Biol 2009;21:344-51.

19. Yudkovsky N, Ranish JA, Hahn S: A transcription reinitiation intermediate that is stabilized by activator. Nature 2000;408:225-9.

20. Licatalosi DD, Geiger G, Minet M, et al.: Functional interaction of yeast pre-mRNA 3' end processing factors with RNA polymerase II. Mol Cell 2002;9:1101-11.

21. Kim M, Ahn SH, Krogan NJ, et al.: Transitions in RNA polymerase II elongation complexes at the $3^{\prime}$ ends of genes. EMBO J 2004;23:354-64.

22. Zhang Z, Fu J, Gilmour DS: CTD-dependent dismantling of the RNA polymerase II elongation complex by the pre-mRNA 3'-end processing factor, Pcf11. Genes Dev 2005;19:1572-80.

23. Zhang Z, Gilmour DS: Pcf11 is a termination factor in Drosophila that dismantles the elongation complex by bridging the CTD of RNA polymerase II to the nascent transcript. Mol Cell 2006;21:65-74.

24. West S, Gromak N, Proudfoot NJ: Human 5' --> 3' exonuclease Xrn2 promotes transcription termination at co-transcriptional cleavage sites. Nature 2004;432:522-5.

25. Kim M, Krogan NJ, Vasiljeva L, et al.: The yeast Rat1 exonuclease promotes transcription termination by RNA polymerase II. Nature 2004;432:517-22.

26. Gromak N, West S, Proudfoot NJ: Pause sites promote transcriptional termination of mammalian RNA polymerase II. Mol Cell Biol 2006;26:3986-96.

27. Skourti-Stathaki K, Proudfoot NJ, Gromak N: Human senataxin resolves RNA/DNA hybrids formed at transcriptional pause sites to promote Xrn2-dependent termination. Mol Cell 2011;42:794-805.

28. Mischo HE, Gomez-Gonzalez B, Grzechnik P, et al.: Yeast Sen1 helicase protects the genome from transcription-associated instability. Mol Cell 2011;41:21-32.

29. Park NJ, Tsao DC, Martinson HG: The two steps of poly(A)-dependent termination, pausing and release, can be uncoupled by truncation of the RNA polymerase II carboxyl-terminal repeat domain. Mol Cell Biol 2004;24:4092-103. 
30. Nag A, Narsinh K, Martinson HG: The poly(A)-dependent transcriptional pause is mediated by CPSF acting on the body of the polymerase. Nat Struct Mol Biol 2007;14:662-9.

31. Kazerouninia A, Ngo B, Martinson HG: Poly(A) signal-dependent degradation of unprocessed nascent transcripts accompanies poly(A) signal-dependent transcriptional pausing in vitro. RNA 2010;16:197-210.

32. Luo W, Johnson AW, Bentley DL: The role of Rat1 in coupling mRNA 3'-end processing to transcription termination: implications for a unified allosteric-torpedo model. Genes Dev 2006;20:954-65.

33. Buratowski S: Progression through the RNA polymerase II CTD cycle. Mol Cell 2009;36:541-6.

34. Egloff S, Dienstbier M, Murphy S: Updating the RNA polymerase CTD code: adding gene-specific layers. Trends Genet 2012;28:333-41.

35. Heidemann M, Hintermair C, Voss K, et al.: Dynamic phosphorylation patterns of RNA polymerase II CTD during transcription. Biochim Biophys Acta 2012.

36. Hsin JP, Manley JL: The RNA polymerase II CTD coordinates transcription and RNA processing. Genes Dev 2012;26:2119-37.

37. Zhang DW, Rodriguez-Molina JB, Tietjen JR, et al.: Emerging Views on the CTD Code. Genet Res Int 2012;2012:347214.

38. Mayer A, Heidemann M, Lidschreiber M, et al.: CTD tyrosine phosphorylation impairs termination factor recruitment to RNA polymerase II. Science 2012;336:1723-5.

39. Egloff S, O'Reilly D, Chapman RD, et al.: Serine-7 of the RNA polymerase II CTD is specifically required for snRNA gene expression. Science 2007;318:1777-9.

40. Egloff S, Szczepaniak SA, Dienstbier M, et al.: The integrator complex recognizes a new double mark on the RNA polymerase II carboxyl-terminal domain. J Biol Chem 2010;285:20564-9.

41. Egloff S, Zaborowska J, Laitem C, et al.: Ser7 phosphorylation of the CTD recruits the RPAP2 Ser5 phosphatase to snRNA genes. Mol Cell 2012;45:111-22.

42. Hintermair $\mathrm{C}$, Heidemann M, Koch F, et al.: Threonine-4 of mammalian RNA polymerase II CTD is targeted by Polo-like kinase 3 and required for transcriptional elongation. EMBO J 2012;31:2784-97.

43. Hsin JP, Sheth A, Manley JL: RNAP II CTD phosphorylated on threonine-4 is required for histone mRNA 3' end processing. Science 2011;334:683-6.

44. Kim H, Erickson B, Luo W, et al.: Gene-specific RNA polymerase II phosphorylation and the CTD code. Nat Struct Mol Biol 2010;17:1279-86.

45. Mayer A, Lidschreiber $M$, Siebert $M$, et al.: Uniform transitions of the general RNA polymerase II transcription complex. Nat Struct Mol Biol 2010;17:1272-8. 
46. Anamika K, Gyenis A, Poidevin L, et al.: RNA polymerase II pausing downstream of core histone genes is different from genes producing polyadenylated transcripts. PLoS One 2012;7:e38769.

47. Zhang DW, Mosley AL, Ramisetty SR, et al.: Ssu72 phosphatase-dependent erasure of phosphoSer7 marks on the RNA polymerase II C-terminal domain is essential for viability and transcription termination. J Biol Chem 2012;287:8541-51.

48. Bataille AR, Jeronimo C, Jacques PE, et al.: A universal RNA polymerase II CTD cycle is orchestrated by complex interplays between kinase, phosphatase, and isomerase enzymes along genes. Mol Cell 2012;45:158-70.

49. Glover-Cutter K, Kim S, Espinosa J, et al.: RNA polymerase II pauses and associates with premRNA processing factors at both ends of genes. Nat Struct Mol Biol 2008;15:71-8.

50. Fuda NJ, Buckley MS, Wei W, et al.: Fcp1 dephosphorylation of the RNA polymerase II C-terminal domain is required for efficient transcription of heat shock genes. Mol Cell Biol 2012;32:3428-37.

51. Svejstrup JQ, Li Y, Fellows J, et al.: Evidence for a mediator cycle at the initiation of transcription. Proc Natl Acad Sci U S A 1997;94:6075-8.

52. Bauren G, Belikov S, Wieslander L: Transcriptional termination in the Balbiani ring 1 gene is closely coupled to 3'-end formation and excision of the 3'-terminal intron. Genes Dev 1998;12:275969.

53. Boireau S, Maiuri P, Basyuk E, et al.: The transcriptional cycle of HIV-1 in real-time and live cells. J Cell Biol 2007;179:291-304.

54. West S, Proudfoot NJ, Dye MJ: Molecular dissection of mammalian RNA polymerase II transcriptional termination. Mol Cell 2008;29:600-10.

55. Martins SB, Rino J, Carvalho T, et al.: Spliceosome assembly is coupled to RNA polymerase II dynamics at the $3^{\prime}$ end of human genes. Nat Struct Mol Biol 2011;18:1115-23.

56. Rigo F, Martinson HG: Polyadenylation releases mRNA from RNA polymerase II in a process that is licensed by splicing. RNA 2009;15:823-36.

57. Egloff S, O'Reilly D, Murphy S: Expression of human snRNA genes from beginning to end. Biochem Soc Trans 2008;36:590-4.

58. Osley MA: The regulation of histone synthesis in the cell cycle. Annu Rev Biochem 1991;60:82761.

59. Marino-Ramirez L, Jordan IK, Landsman D: Multiple independent evolutionary solutions to core histone gene regulation. Genome Biol 2006;7:R122.

60. Kuhlman TC, Cho H, Reinberg D, et al.: The general transcription factors IIA, IIB, IIF, and IIE are required for RNA polymerase II transcription from the human U1 small nuclear RNA promoter. Mol Cell Biol 1999;19:2130-41. 


\section{Zaborowska J, Taylor A, Murphy S: A novel TBP-TAF complex on RNA polymerase II-transcribed} snRNA genes. Transcription 2012;3:92-104.

62. Beaudoing E, Freier S, Wyatt JR, et al.: Patterns of variant polyadenylation signal usage in human genes. Genome Res 2000;10:1001-10.

63. Tian B, Hu J, Zhang $\mathrm{H}$, et al.: A large-scale analysis of mRNA polyadenylation of human and mouse genes. Nucleic Acids Res 2005;33:201-12.

64. Sheets MD, Ogg SC, Wickens MP: Point mutations in AAUAAA and the poly (A) addition site: effects on the accuracy and efficiency of cleavage and polyadenylation in vitro. Nucleic Acids Res 1990;18:5799-805.

65. Ozsolak F, Kapranov P, Foissac S, et al.: Comprehensive polyadenylation site maps in yeast and human reveal pervasive alternative polyadenylation. Cell 2010;143:1018-29.

66. Mandel CR, Bai Y, Tong L: Protein factors in pre-mRNA 3'-end processing. Cell Mol Life Sci 2008;65:1099-122.

67. Shi Y, Di Giammartino DC, Taylor D, et al.: Molecular architecture of the human pre-mRNA 3' processing complex. Mol Cell 2009;33:365-76.

68. Takagaki Y, Ryner LC, Manley JL: Four factors are required for 3'-end cleavage of pre-mRNAs. Genes Dev 1989;3:1711-24.

69. Ryan K, Calvo O, Manley JL: Evidence that polyadenylation factor CPSF-73 is the mRNA 3' processing endonuclease. RNA 2004;10:565-73.

70. Takagaki Y, Manley JL: RNA recognition by the human polyadenylation factor CstF. Mol Cell Biol 1997;17:3907-14.

71. Martin G, Gruber AR, Keller W, et al.: Genome-wide analysis of pre-mRNA 3' end processing reveals a decisive role of human cleavage factor I in the regulation of $3^{\prime}$ UTR length. Cell Rep 2012;1:753-63.

72. Kerwitz $\mathrm{Y}$, Kuhn $\mathrm{U}$, Lilie $\mathrm{H}$, et al.: Stimulation of poly(A) polymerase through a direct interaction with the nuclear poly(A) binding protein allosterically regulated by RNA. EMBO J 2003;22:3705-14.

73. Kuhn $\mathrm{U}$, Gundel $\mathrm{M}$, Knoth $\mathrm{A}$, et al.: Poly(A) tail length is controlled by the nuclear poly(A)-binding protein regulating the interaction between poly $(\mathrm{A})$ polymerase and the cleavage and polyadenylation specificity factor. J Biol Chem 2009;284:22803-14.

74. Wang Y, Fairley JA, Roberts SG: Phosphorylation of TFIIB links transcription initiation and termination. Curr Biol 2010;20:548-53.

75. Dantonel JC, Murthy KG, Manley JL, et al.: Transcription factor TFIID recruits factor CPSF for formation of 3' end of mRNA. Nature 1997;389:399-402.

76. Calvo O, Manley JL: Evolutionarily conserved interaction between CstF-64 and PC4 links transcription, polyadenylation, and termination. Mol Cell 2001;7:1013-23. 
77. McCracken S, Fong N, Yankulov K, et al.: The C-terminal domain of RNA polymerase II couples mRNA processing to transcription. Nature 1997;385:357-61.

78. Gnatt AL, Cramer P, Fu J, et al.: Structural basis of transcription: an RNA polymerase II elongation complex at 3.3 A resolution. Science 2001;292:1876-82.

79. Ghazy MA, Gordon JM, Lee SD, et al.: The interaction of Pcf11 and Clp1 is needed for mRNA 3'end formation and is modulated by amino acids in the ATP-binding site. Nucleic Acids Res 2012;40:1214-25.

80. Sadowski M, Dichtl B, Hubner W, et al.: Independent functions of yeast Pcf11p in pre-mRNA 3' end processing and in transcription termination. EMBO J 2003;22:2167-77.

81. Meinhart A, Cramer P: Recognition of RNA polymerase Il carboxy-terminal domain by 3'-RNAprocessing factors. Nature 2004;430:223-6.

82. Marzluff WF, Gongidi P, Woods KR, et al.: The human and mouse replication-dependent histone genes. Genomics 2002;80:487-98.

83. Marzluff WF, Duronio RJ: Histone mRNA expression: multiple levels of cell cycle regulation and important developmental consequences. Curr Opin Cell Biol 2002;14:692-9.

84. Rattray AM, Muller B: The control of histone gene expression. Biochem Soc Trans 2012;40:880-5.

85. Chodchoy N, Pandey NB, Marzluff WF: An intact histone 3'-processing site is required for transcription termination in a mouse histone H2a gene. Mol Cell Biol 1991;11:497-509.

86. Adamson TE, Price DH: Cotranscriptional processing of Drosophila histone mRNAs. Mol Cell Biol 2003;23:4046-55.

87. Scharl EC, Steitz JA: The site of 3 ' end formation of histone messenger RNA is a fixed distance from the downstream element recognized by the U7 snRNP. EMBO J 1994;13:2432-40.

88. Furger A, Schaller A, Schumperli D: Functional importance of conserved nucleotides at the histone RNA 3' processing site. RNA 1998;4:246-56.

89. Dominski Z, Yang XC, Marzluff WF: The polyadenylation factor CPSF-73 is involved in histone-premRNA processing. Cell 2005;123:37-48.

90. Yang XC, Sullivan KD, Marzluff WF, et al.: Studies of the $5^{\prime}$ exonuclease and endonuclease activities of CPSF-73 in histone pre-mRNA processing. Mol Cell Biol 2009;29:31-42.

91. Kolev NG, Steitz JA: Symplekin and multiple other polyadenylation factors participate in 3'-end maturation of histone mRNAs. Genes Dev 2005;19:2583-92.

92. Wagner EJ, Burch BD, Godfrey AC, et al.: A genome-wide RNA interference screen reveals that variant histones are necessary for replication-dependent histone pre-mRNA processing. Mol Cell 2007;28:692-9. 
93. Jaeger S, Martin F, Rudinger-Thirion J, et al.: Binding of human SLBP on the 3'-UTR of histone precursor H4-12 mRNA induces structural rearrangements that enable U7 snRNA anchoring. Nucleic Acids Res 2006;34:4987-95.

94. Dominski Z, Erkmann JA, Yang X, et al.: A novel zinc finger protein is associated with U7 snRNP and interacts with the stem-loop binding protein in the histone pre-mRNP to stimulate 3 '-end processing. Genes Dev 2002;16:58-71.

95. Azzouz TN, Gruber A, Schumperli D: U7 snRNP-specific Lsm11 protein: dual binding contacts with the $100 \mathrm{kDa}$ zinc finger processing factor (ZFP100) and a ZFP100-independent function in histone RNA 3' end processing. Nucleic Acids Res 2005;33:2106-17.

96. Wagner EJ, Ospina JK, Hu Y, et al.: Conserved zinc fingers mediate multiple functions of ZFP100, a U7snRNP associated protein. RNA 2006;12:1206-18.

97. Yang XC, Burch BD, Yan Y, et al.: FLASH, a proapoptotic protein involved in activation of caspase8, is essential for 3' end processing of histone pre-mRNAs. Mol Cell 2009;36:267-78.

98. Barcaroli D, Bongiorno-Borbone L, Terrinoni A, et al.: FLASH is required for histone transcription and S-phase progression. Proc Natl Acad Sci U S A 2006;103:14808-12.

99. Stiller JW, McConaughy BL, Hall BD: Evolutionary complementation for polymerase II CTD function. Yeast 2000;16:57-64.

100. Schwer B, Shuman S: Deciphering the RNA polymerase II CTD code in fission yeast. Mol Cell 2011;43:311-8.

101. Pirngruber J, Shchebet A, Schreiber L, et al.: CDK9 directs H2B monoubiquitination and controls replication-dependent histone mRNA 3'-end processing. EMBO Rep 2009;10:894-900.

102. Medlin J, Scurry A, Taylor A, et al.: P-TEFb is not an essential elongation factor for the intronless human U2 snRNA and histone H2b genes. EMBO J 2005;24:4154-65.

103. Jawdekar GW, Henry RW: Transcriptional regulation of human small nuclear RNA genes. Biochim Biophys Acta 2008;1779:295-305.

104. Hernandez N, Weiner AM: Formation of the $3^{\prime}$ end of $\mathrm{U} 1$ snRNA requires compatible snRNA promoter elements. Cell 1986;47:249-58.

105. Skuzeski JM, Lund E, Murphy JT, et al.: Synthesis of human U1 RNA. II. Identification of two regions of the promoter essential for transcription initiation at position +1 . J Biol Chem 1984;259:8345-52.

106. Murphy JT, Skuzeski JT, Lund E, et al.: Functional elements of the human U1 RNA promoter. Identification of five separate regions required for efficient transcription and template competition. J Biol Chem 1987;262:1795-803.

107. Sadowski CL, Henry RW, Lobo SM, et al.: Targeting TBP to a non-TATA box cis-regulatory element: a TBP-containing complex activates transcription from snRNA promoters through the PSE. Genes Dev 1993;7:1535-48. 
108. Baillat D, Hakimi MA, Naar AM, et al.: Integrator, a multiprotein mediator of small nuclear RNA processing, associates with the C-terminal repeat of RNA polymerase II. Cell 2005;123:265-76.

109. Cuello $P$, Boyd DC, Dye MJ, et al.: Transcription of the human U2 snRNA genes continues beyond the 3 ' box in vivo. EMBO J 1999;18:2867-77.

110. Kunkel GR, Pederson T: Transcription boundaries of U1 small nuclear RNA. Mol Cell Biol 1985;5:2332-40.

111. Medlin JE, Uguen P, Taylor A, et al.: The C-terminal domain of pol II and a DRB-sensitive kinase are required for 3' processing of U2 snRNA. EMBO J 2003;22:925-34.

112. Jacobs EY, Ogiwara I, Weiner AM: Role of the C-terminal domain of RNA polymerase II in U2 snRNA transcription and 3' processing. Mol Cell Biol 2004;24:846-55.

113. Uguen $\mathrm{P}$, Murphy S: The $3^{\prime}$ ends of human pre-snRNAs are produced by RNA polymerase II CTDdependent RNA processing. EMBO J 2003;22:4544-54.

114. Ramamurthy L, Ingledue TC, Pilch DR, et al.: Increasing the distance between the snRNA promoter and the 3' box decreases the efficiency of snRNA 3'-end formation. Nucleic Acids Res 1996;24:4525-34.

115. Hernandez $N$, Lucito R: Elements required for transcription initiation of the human U2 snRNA gene coincide with elements required for snRNA 3' end formation. EMBO J 1988;7:3125-34.

116. de Vegvar HE, Lund E, Dahlberg JE: 3' end formation of U1 snRNA precursors is coupled to transcription from snRNA promoters. Cell 1986;47:259-66.

117. Steinmetz EJ, Conrad NK, Brow DA, et al.: RNA-binding protein Nrd1 directs poly(A)independent 3'-end formation of RNA polymerase II transcripts. Nature 2001;413:327-31.

118. Arigo JT, Eyler DE, Carroll KL, et al.: Termination of cryptic unstable transcripts is directed by yeast RNA-binding proteins Nrd1 and Nab3. Mol Cell 2006;23:841-51.

119. Thiebaut M, Kisseleva-Romanova E, Rougemaille M, et al.: Transcription termination and nuclear degradation of cryptic unstable transcripts: a role for the nrd1-nab3 pathway in genome surveillance. Mol Cell 2006;23:853-64.

120. Vasiljeva L, Buratowski S: Nrd1 interacts with the nuclear exosome for 3' processing of RNA polymerase II transcripts. Mol Cell 2006;21:239-48.

121. Steinmetz EJ, Brow DA: Repression of gene expression by an exogenous sequence element acting in concert with a heterogeneous nuclear ribonucleoprotein-like protein, $\mathrm{Nrd} 1$, and the putative helicase Sen1. Mol Cell Biol 1996;16:6993-7003.

122. Kawauchi J, Mischo H, Braglia P, et al.: Budding yeast RNA polymerases I and II employ parallel mechanisms of transcriptional termination. Genes Dev 2008;22:1082-92.

123. Steinmetz EJ, Warren CL, Kuehner JN, et al.: Genome-wide distribution of yeast RNA polymerase II and its control by Sen1 helicase. Mol Cell 2006;24:735-46. 


\begin{abstract}
124. Steinmetz EJ, Brow DA: Control of pre-mRNA accumulation by the essential yeast protein Nrd1 requires high-affinity transcript binding and a domain implicated in RNA polymerase II association. Proc Natl Acad Sci U S A 1998;95:6699-704.
\end{abstract}

125. Carroll KL, Pradhan DA, Granek JA, et al.: Identification of cis elements directing termination of yeast nonpolyadenylated snoRNA transcripts. Mol Cell Biol 2004;24:6241-52.

126. Conrad NK, Wilson SM, Steinmetz EJ, et al.: A yeast heterogeneous nuclear ribonucleoprotein complex associated with RNA polymerase II. Genetics 2000;154:557-71.

127. Carroll KL, Ghirlando R, Ames JM, et al.: Interaction of yeast RNA-binding proteins Nrd1 and Nab3 with RNA polymerase II terminator elements. RNA 2007;13:361-73.

128. Gudipati RK, Villa T, Boulay J, et al.: Phosphorylation of the RNA polymerase II C-terminal domain dictates transcription termination choice. Nat Struct Mol Biol 2008;15:786-94.

129. Kubicek K, Cerna H, Holub P, et al.: Serine phosphorylation and proline isomerization in RNAP II CTD control recruitment of Nrd1. Genes Dev 2012;26:1891-6.

130. Vasiljeva L, Kim M, Mutschler H, et al.: The Nrd1-Nab3-Sen1 termination complex interacts with the Ser5-phosphorylated RNA polymerase II C-terminal domain. Nat Struct Mol Biol 2008;15:795804.

131. He X, Khan AU, Cheng $\mathrm{H}$, et al.: Functional interactions between the transcription and mRNA $3^{\prime}$ end processing machineries mediated by Ssu72 and Sub1. Genes Dev 2003;17:1030-42.

132. Reyes-Reyes M, Hampsey M: Role for the Ssu72 C-terminal domain phosphatase in RNA polymerase II transcription elongation. Mol Cell Biol 2007;27:926-36.

133. Singh BN, Hampsey M: A transcription-independent role for TFIIB in gene looping. Mol Cell 2007;27:806-16.

134. Tan-Wong SM, French JD, Proudfoot NJ, et al.: Dynamic interactions between the promoter and terminator regions of the mammalian BRCA1 gene. Proc Natl Acad Sci U S A 2008;105:5160-5.

135. Rondon AG, Mischo HE, Kawauchi J, et al.: Fail-safe transcriptional termination for proteincoding genes in S. cerevisiae. Mol Cell 2009;36:88-98.

136. Niwa M, Rose SD, Berget SM: In vitro polyadenylation is stimulated by the presence of an upstream intron. Genes Dev 1990;4:1552-9.

137. Rigo F, Martinson HG: Functional coupling of last-intron splicing and 3 '-end processing to transcription in vitro: the poly(A) signal couples to splicing before committing to cleavage. Mol Cell Biol 2008;28:849-62.

138. Dye MJ, Proudfoot NJ: Terminal exon definition occurs cotranscriptionally and promotes termination of RNA polymerase II. Mol Cell 1999;3:371-8. 
139. Kyburz A, Friedlein A, Langen $H$, et al.: Direct interactions between subunits of CPSF and the U2 snRNP contribute to the coupling of pre-mRNA 3' end processing and splicing. Mol Cell 2006;23:195205.

140. Uguen P, Murphy S: 3'-box-dependent processing of human pre-U1 snRNA requires a combination of RNA and protein co-factors. Nucleic Acids Res 2004;32:2987-94.

141. Lykke-Andersen S, Mapendano CK, Jensen TH: An ending is a new beginning: transcription termination supports re-initiation. Cell Cycle 2011;10:863-5.

142. Shandilya J, Roberts SG: The transcription cycle in eukaryotes: From productive initiation to RNA polymerase II recycling. Biochim Biophys Acta 2012;1819:391-400.

143. Darzacq $X$, Shav-Tal $Y$, de Turris $V$, et al.: In vivo dynamics of RNA polymerase II transcription. Nat Struct Mol Biol 2007;14:796-806.

144. Marguerat S, Schmidt A, Codlin S, et al.: Quantitative analysis of fission yeast transcriptomes and proteomes in proliferating and quiescent cells. Cell 2012;151:671-83.

Figure captions

Fig. 1: The RNAPII transcription cycle

Illustration showing the changes of RNAPII during transcription and recycling based on transcription of a polyA gene. Colored circles of the respective residue indicate phosphorylation of the CTD: Tyrosine 1 (Y1) in yellow, Serine 2 (S2) in green, Threonine 4 (T4) in purple, Serine 5 (S5) in red and Serine 7 (S7) in blue. For S2 and S7, intense colors illustrate high levels of phosphorylation whereas less intense coloration indicates lower levels of phosphorylation. XRN2 is depicted with a yellow pacman. For further details see text.

Fig 2: Overview of different types of RNAPII transcribed genes and their 3'end processing machineries.

(A) Schematic illustration of the general lengths of polyA (green), histone (red) and snRNA (purple) genes (terminators included). See text for details. (B) Overview of systems engaged with 3'end processing of precursor RNAs arising from polyA genes, histone genes and snRNA genes as well as 


\begin{abstract}
3'end processing by the NNS complex. Top panels show sequence-elements and complexes involved
\end{abstract} with an arrow emphasizing the endoribonuclease catalyzing the cleavage reaction. Lower panels show the processed RNA product, which in the case of NNS-mediated processing is further processed by TRAMP and the RNA exosome. Complexes involved in 3'end processing of polyA mRNAs are depicted in shades of green, for histone mRNAs in shades of red and for snRNA in purple. The machineries responsible for 3'end processing of histone and polyA mRNAs share several factors, which are in shades of green (see text for further details). The proteins of the NNS complex are depicted in shades of grey.

Tables

[Please insert any tables here]

Further Reading/Resources

[Please insert any further reading/resources here]

Related Articles

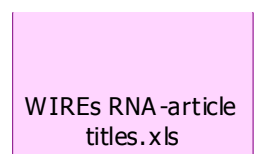

\begin{tabular}{|l|l|}
\hline \multicolumn{1}{|c|}{ Article ID } & \multicolumn{1}{c|}{ Article title } \\
\hline 141 & Overview: Mechanisms of 3' end formation \\
\hline 151 & Polyadenylation and transcription termination \\
\hline 136 & Non mRNA 3' end formation \\
\hline
\end{tabular}

Comment [A7]: Note: You must provide permissions (or waivers) from the copyright holders of all previously published materials, even if they are adapted. To acquire permissions, use the request form provided in your Author Guide or request permission from registered publishers via the Copyright Clearance Center's "Rightslink" page (http://www.copyright.com).

Comment [A8]: Make sure to include appropriate credit lines for any previously published materials.

\section{Comment [A9]:}

For readers who may want more information on concepts in your article, provide full references here to additional recommended resources (books,

articles, websites, links to multimedia, etc.) that are not included in the reference section. Please do not include links to non-academic sites such as Wikipedia or YouTube, or to impermanent websites.

Comment [A10]: Double-click on this icon to see a list of working article titles in WIREs RNA. Please choose 1-3 related articles to which your article may usefully be linked and enter them into the table below. 


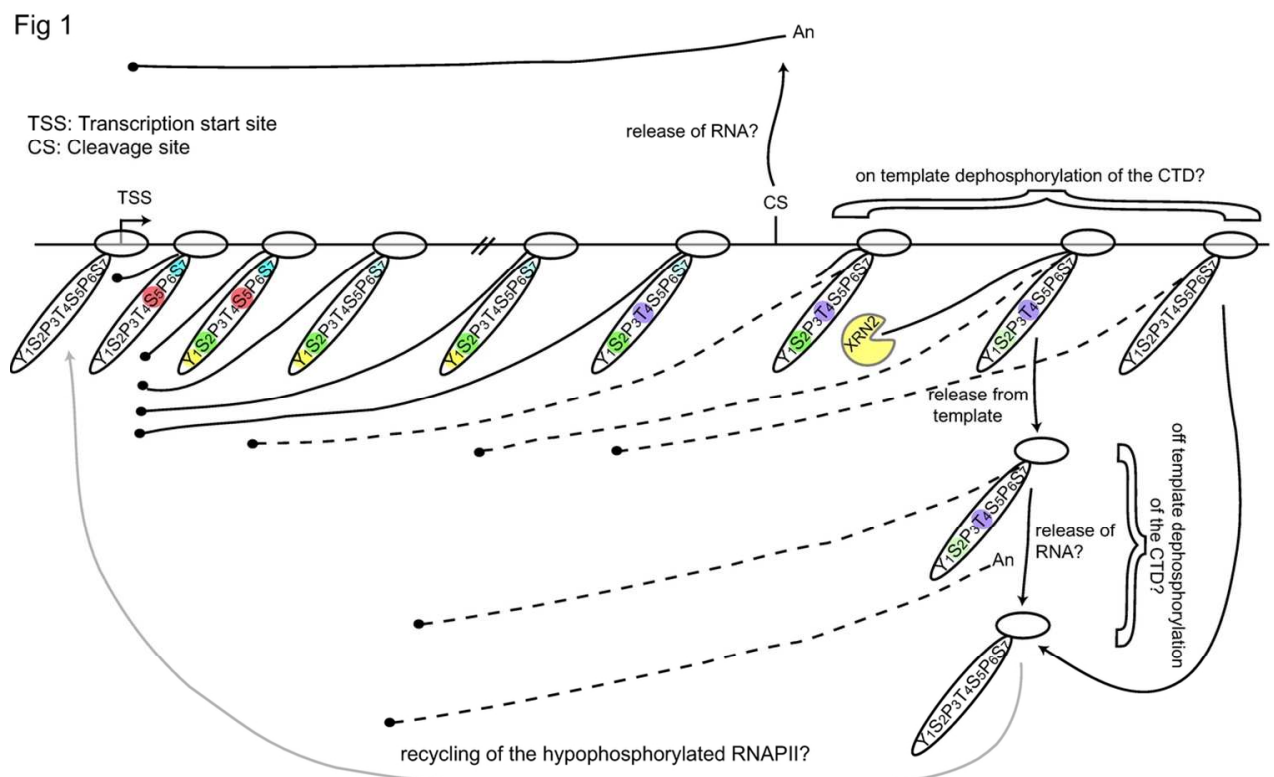

Fig. 1: The RNAPII transcription cycle

Illustration showing the changes of RNAPII during transcription and recycling based on transcription of a polyA gene. Colored circles of the respective residue indicate phosphorylation of the CTD: Tyrosine 1 (Y1) in yellow, Serine 2 (S2) in green, Threonine 4 (T4) in purple, Serine 5 (S5) in red and Serine 7 (S7) in blue. For S2 and S7, intense colors illustrate high levels of phosphorylation whereas less intense coloration indicates lower levels of phosphorylation. XRN2 is depicted with a yellow pacman. For further details see text.

\section{$121 \times 72 \mathrm{~mm}(300 \times 300 \mathrm{DPI})$}




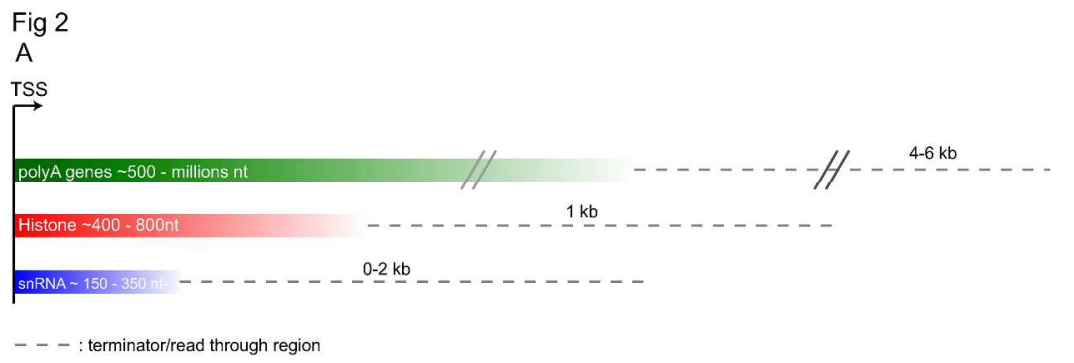

B

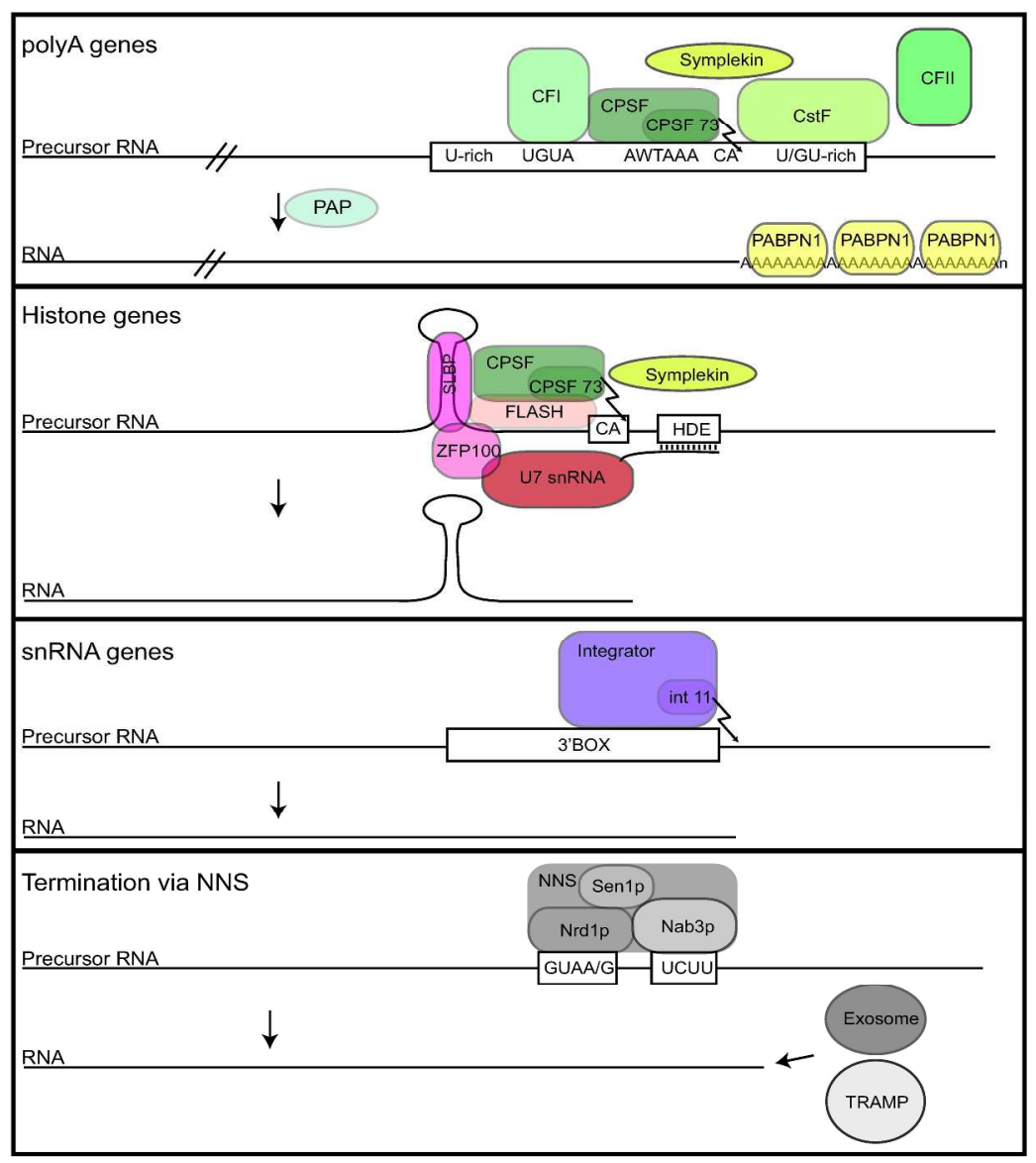

Fig 2: Overview of different types of RNAPII transcribed genes and their 3'end processing machineries. (A) Schematic illustration of the general lengths of polyA (green), histone (red) and snRNA (purple) genes (terminators included). See text for details. (B) Overview of systems engaged with 3 'end processing of precursor RNAs arising from polyA genes, histone genes and snRNA genes as well as 3'end processing by the NNS complex. Top panels show sequence-elements and complexes involved with an arrow emphasizing the endoribonuclease catalyzing the cleavage reaction. Lower panels show the processed RNA product, which in the case of NNS-mediated processing is further processed by TRAMP and the RNA exosome.

Complexes involved in 3'end processing of polyA mRNAs are depicted in shades of green, for histone mRNAs in shades of red and for snRNA in purple. The machineries responsible for 3 'end processing of histone and polyA mRNAs share several factors, which are in shades of green (see text for further details). The proteins of the NNS complex are depicted in shades of grey. 


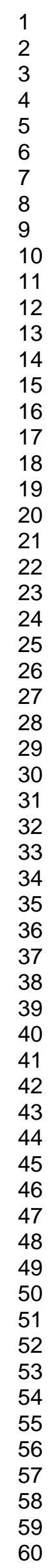

